\title{
Changes in content of major phenolic compounds during leaf development of sea buckthorn (Hippophaë rhamnoides L.)
}

\author{
Anne Morgenstern ${ }^{1,2}$, Anders Ekholm¹, Petra Scheewe ${ }^{2}$ and Kimmo Rumpunen², \\ ${ }^{1}$ Swedish University of Agricultural Sciences, Department of Plant Breeding, Balsgård, Fjälkestadsvägen 459, \\ 29194 Kristianstad, Sweden \\ ${ }^{2}$ Hochschule für Technik und Wirtschaft Dresden (University of Applied Sciences), Faculty of Agriculture and Landscape \\ Management, Pillnitzer Platz 2, 01326 Dresden, Germany \\ * e-mail: kimmo.rumpunen@slu.se
}

\begin{abstract}
Content of total phenolic compounds and antioxidant capacity (FRAP) were investigated in the leaves of three sea buckthorn (Hippophaë rhamnoides L.) cultivars: 'Otradnaja', 'Gibrid Pertjika' and 'Ljubitelskaja', at different dates. In addition, major phenolic compounds (catechin, kaempferol, quercetin, epigallocatechin, kaempferol-3-O-glucoside, quercetin-3-O-galactoside, isorhamnetin-3-O-glucoside, rutin, gallic acid, procyanidin monomer glycoside, procyanidin dimer aglycone and hydrolyzable tannins I-III) were determined in 'Ljubitelskaja'. Antioxidant capacity and the content of total phenolic compounds fluctuated during April, May and June, and then increased until the end of July, when the highest values were observed. Total phenolic compounds were strongly correlated with FRAP. Levels were generally higher in 'Ljubitelskaja' than in 'Otradnaja' and 'Gibrid Pertjika'. In 'Ljubitelskaja', hydrolyzable tannins I-III occurred in higher amounts than did any of the other studied phenolic compounds. The developmental stage of the leaves (harvesting date) had a strong influence on content of phenolic compounds and should be carefully considered when harvesting sea buckthorn leaves for different purposes.
\end{abstract}

Key words: antioxidant capacity, flavonoids, FRAP, polyphenols, tannins

\section{Introduction}

Sea buckthorn (Hippophaë L.) belongs to the family Elaeagnaceae. The most widely distributed species, H. rhamnoides, occurs in Central and Northern regions of Europe and Asia, and is divided into eight subspecies (Swenson and Bartish 2003). The plant is a thorny shrub, which can reach approx. six meters in height. About $90 \%$ of the genetic resources are located in China, but northern India, Russia and Mongolia are also rich in sea buckthorn (Singh 2003, Erkkola and Yang 2003, Ruan et al. 2013). The sun-loving plant grows in mountainous and coastal areas on well-drained soils, and it is well adapted to dry conditions. Sea buckthorn is often used as a pioneer plant to counteract soil erosion and to improve soil fertility through its $N_{2}$ fixation capacity (Singh 2003, Qinxiao and Hongyan 2003). These features, together with the valuable fruits, make sea buckthorn an interesting multipurpose crop for sustainable agriculture.

Sea buckthorn fruits are important sources of vitamins, natural antioxidants, oils, triterpenes and other bioactive substances (Singh 2006, Geetha et al. 2002, Tsybikova et al. 2006). Both fruits (Rösch et al. 2003) and leaves (Yoshida et al. 1991, Heinäaho et al. 2006, Zu et al. 2006, Moilanen et al. 2013) are rich in polyphenols, and are part of Asian traditional medicine for treatment of, e.g., skin disorders (Upadhyay et al. 2011, Erkkola and Yang, 2003). Beneficial effects of sea buckthorn fruits have been documented through in vitro studies, animal trials and clinical intervention studies. Thus sea buckthorn pulp oil can inhibit platelet aggregation (Johansson et al. 2000), improve atopic dermatitis (Yang et al. 1999) and alleviate symptoms connected with dry eyes (Larmo et al. 2010) in humans. Sea buckthorn puree can lower the plasma high-sensitivity c-reactive protein level (Larmo et al. 2008), which is a marker for inflammation and a risk factor for cardiovascular disease. Furthermore, ethanol-soluble components of sea buckthorn fruits have been shown to affect postprandial hyperglycemia and insulin response (Lehtonen et al. 2010a) and the beneficial flavonols of sea buckthorn berries have proven to be highly bioavailable (Larmo et al. 2009, Lehtonen et al. 2010b). 
In addition to fruits, also sea buckthorn leaves have potential beneficial effects. In animal models an aqueous extract of sea buckthorn leaves has shown adaptogenic properties (Saggu et al. 2007, Saggu and Kumar 2008) and has proven especially efficient for wound healing (Upadhyay et al. 2011), an effect that in part may be attributed to extractable polyphenols (Upadhyay et al. 2010). In vitro studies have, in addition to anti-inflammatory (Jayashankar et al. 2012) and free radical scavenging effects (Padwad et al. 2006), revealed strong anti-viral (Tolkachev and Sheichenko 2006, Jain et al. 2008) and $\alpha$-glucosidase inhibitory effects (Kim et al. 2011) of leaf extracts that also may be attributed to the content of polyphenols. Detailed knowledge about factors influencing the content of sea buckthorn leaf phytochemicals is therefore much needed.

Effects of different organic farming methods on the content of phenolic compounds in sea buckthorn leaves have previously been investigated on cultivars of $H$. rhamnoides subsp. rhamnoides (Heinäaho et al. 2006). Arimboor et al. (2008) studied the content of phenolic acids in leaves of $H$. rhamnoides subsp. turkestanica and Rongfu et al. (2003) studied the seasonal changes in content of total flavones in leaves of $H$. rhamnoides subsp. sinensis. In this study we investigate the influence of development stage of sea buckthorn leaves of $H$. rhamnoides hybrid cultivars on the total antioxidant capacity, total phenolic compounds, and on the content of major single phenolic compounds.

\section{Material and methods}

\section{Plant material}

Leaf samples were collected from three sea buckthorn (H. rhamnoides) cultivars ('Gibrid Pertjika', 'Otradnaja' and 'Ljubitelskaja') of Russian origin grown at Balsgård, Kristianstad, in the south of Sweden. The plants were grown in a randomized field trial in three blocks, surrounded by $\mathrm{H}$. rhamnoides seedlings as border plants. Each block contained nine plants per cultivar, and the trial was planted in 1997. The plants were not pruned, irrigated or fertilized during the sampling period. Grass was used as mulch. The leaves were sampled on eight occasions at an interval of two weeks from the end of April to the end of July in 2007: April 23, May 7, May 21, June 4, June 18, July 2, July 16 and July 30 .

On each sampling date, 12 leaves from each of two plants per cultivar and block were sampled to obtain a representative sample. Leaves were picked from the middle part of the branches. All samples of a cultivar were then pooled before subsampling for biochemical analyses.

\section{Measurements and preparation of leaves}

Leaf length was measured, and the fresh and dry weight was determined (in triplicates) before and after freeze-drying. Dry matter of leaves was calculated, and the freeze-dried leaves were then milled to a fine powder with an IKA ${ }^{\circledR}$ type $\mathrm{A} 10$ mill, the powder was stored frozen at $-20{ }^{\circ} \mathrm{C}$ until used for analyses of total antioxidant capacity and total phenolic compounds. For 'Ljubitelskaja' major single phenolic compounds were also analyzed.

\section{FRAP analysis of antioxidant capacity}

Analysis of antioxidant capacity was undertaken with the FRAP (Ferric Reducing Ability of Plasma) method according to Benzie and Strain (1996) with minor modifications. Leaf powder ( $25 \mathrm{mg}$ ) was extracted in duplicate with 1 $\mathrm{ml}$ of $90 \% \mathrm{MeOH}$. After a 15 min extraction in ultrasonic bath the samples were centrifuged for $10 \mathrm{~min}$. The supernatant was then diluted 50 times by mixing an aliquot of $20 \mu \mathrm{l}$ with $980 \mu \mathrm{l}$ of $90 \% \mathrm{MeOH}$. A reagent solution was prepared as follows: $100 \mathrm{ml}$ of acetate buffer solution (pH 3.61) was mixed with $10 \mathrm{ml}$ of 2, 4, 6-Tris(2-pyridyl)-striazine (TPTZ) solution and $10 \mathrm{ml}$ of iron(III) chloride hexahydrate $\left(\mathrm{Fe}^{3+}\right)$ solution. The TPTZ solution consisted of $312 \mathrm{mg}$ of TPTZ powder (Fluka) mixed with $100 \mathrm{ml}$ of $40 \mathrm{mM} \mathrm{HCl}$ (30\%, Suprapur ${ }^{\circ}$, Merck) in an ultrasonic bath for $3 \mathrm{~min}$. A $20 \mathrm{mM} \mathrm{Fe}^{3+}$ solution was made from iron(III) chloride hexahydrate (Fluka) and a stock solution of $2 \mathrm{mM}$ $\mathrm{Fe}^{2+}$ was made from iron(II) sulfate heptahydrate (Fluka) using distilled water. Then standards of 800,400 and 200 $\mu \mathrm{M} \mathrm{Fe}{ }^{2+}$ solutions were prepared. Absorbance was recorded at $593 \mathrm{~nm}$ following a $240 \mathrm{~s}$ reaction period. The reagent solution was kept in a water bath at $37{ }^{\circ} \mathrm{C}$ during the whole time. For analysis, $1 \mathrm{ml}$ of the reagent solution was put into a $10 \times 4 \times 45 \mathrm{~mm}$ cuvette set in a Shimadzu (UV-2101PC) spectrophotometer, $10 \mu \mathrm{l}$ of the standard solution or the sample were then added and mixed with the reagent solution in the cuvette. Each diluted sample was analyzed in triplicate against a blank that contained only the reagent. 


\section{Total phenolic compounds analysis}

Total phenolic compounds analysis (TP) was conducted with Folin-Ciocalteu's reagent (BDH) according to Singleton and Rosst (1965) with minor modifications. Leaf powder $(25 \mathrm{mg}$ ) was extracted in duplicates with $1 \mathrm{ml}$ of $50 \%$ EtOH (containing $0.338 \%$ of orthophosphoric acid), ultrasonicated for 15 min and centrifuged for 10 min. Then the extracts were diluted four times by mixing an aliquot of $250 \mu \mathrm{l}$ with $750 \mu \mathrm{l}$ of $50 \%$ EtOH solution. Next, 10 $\mu \mathrm{l}$ of each diluted extract was mixed with $100 \mu \mathrm{l}$ of $5 \%$ aqueous EtOH, $2 \mathrm{ml}$ of $15 \%$ sodium carbonate monohydrate (175.05 g l-1 of $\mathrm{Na}_{2} \mathrm{CO}_{3} \bullet \mathrm{H}_{2} \mathrm{O}$ ), $200 \mu$ of Folin-Ciocalteu's phenol reagent and $1 \mathrm{ml}$ of distilled water in a 10 x 10 x $45 \mathrm{~mm}$ cuvette. The samples were kept at room temperature for $2 \mathrm{~h}$ before spectrophotometric analysis. A standard stock solution of $705 \mu \mathrm{M}$ gallic acid in $5 \% \mathrm{EtOH}$ was prepared and diluted to make a 5 point standard curve for quantification. Absorbance was recorded at $765 \mathrm{~nm}$ using a Shimadzu (UV-2101PC) spectrophotometer. Standards and samples were analyzed in triplicates. The total content of phenolic compounds was quantified as gallic acid equivalents (GAE).

\section{HPLC-MS analysis of major single phenolic compounds}

For the HPLC-MS analysis of major single phenolic compounds samples were extracted in triplicates using the same procedure as for total phenolic compounds analysis and samples were kept at $-20^{\circ} \mathrm{C}$ until use. All extracts were diluted 20 times before analysis. Standards (Extrasynthèse, France) were prepared as follows. First, a standard mix A (StM A) was prepared: catechin, epicatechin, rutin and gallic acid were dissolved in $100 \%$ EtOH to obtain concentrations of $82.5,70.6,47.4$ and $65.1 \mu \mathrm{g} / \mathrm{ml}$, respectively. Single standards of epigallocatechin, isorhamnetin, isorhamnetin-3-O-glucoside, kaempferol and kaempferol-3-O-glucoside, were also dissolved in $100 \%$ EtOH to obtain concentrations of $6.6,5.6,10.0,9.6,4.0,6.44$ and $9.78 \mu \mathrm{g} / \mathrm{ml}$, respectively. After that, $0.1 \mathrm{ml}$ of each single standard was mixed with $0.3 \mathrm{ml}$ of StM A to obtain standard mix B (StM B). StM B was then diluted ten times with $50 \% \mathrm{EtOH}$ and used for analysis. HPLC-MS analyses of major single phenolic compounds were undertaken with an API 150 EX Turbo lonspray mass spectrometer according to a slightly modified method of Salminen et al. (1999). The HPLC system consisted of a Perkin Elmer 200 autosampler, two Perkin Elmer LC-200 Micro pumps, a guard column LiChroCART 4-4 100 RP-18 (5 $\mu \mathrm{m})$ and a column LiChroCART 75-4 Superspher 100 RP-18. Injection volume was $8 \mu$ l. Elution was carried out at a flow rate of $1 \mathrm{ml} \mathrm{min}^{-1}$. The binary mobile phase consisted of $(A) 0.4 \%$ formic acid and (B) MeCN (acetonitrile). The gradient elution profile was $0 \%$ B for 3 min, then from 3 to 30 min it was gradually increased to $30 \%$, from 30 to 35 min gradually increased to $40 \%$, and was then kept steady until 38 min when it was gradually decreased to $0 \%$ until $42.5 \mathrm{~min}$. The mass spectrometer was operated in a negative mode. Mass spectra were obtained between 125 and $2250 \mathrm{amu}$. The nebulizer gas and the curtain gas were 9 and 12 $\mathrm{ml} \mathrm{min}{ }^{-1}$, respectively. Temperature was $300{ }^{\circ} \mathrm{C}$ and ion spray voltage (IS) was -4000 . In the scan mode the orifice plate potential, the focusing ring potential and the entrance potential were $-35 \mathrm{~V},-220 \mathrm{~V}$ and $-8.5 \mathrm{~V}$, respectively. Based on initial tests in total 23 [M-H] ions (m/z 169.1, 285.1, 289.1, 301.2, 305.2, 315.2, 435.2, 441.2, 447.3, $451.2,457.4,463.4,477.4,577.2,593.4,609.5,623.5,739.3,901.2,935.5,937.2,953.5,1109.5)$ were selected for the HPLC-MS analysis. Of these reliable results could be obtained for 14 ions. The hydrolyzable tannins were quantified as gallic acid equivalents (GAE) since no other standards were available. For the same reason the procyanidin monomer glycoside and procyanidin dimer aglycone were quantified as catechin equivalents. Quercetin-3-O-galactoside and quercetin were quantified as rutin.

\section{Statistical analyses}

For chemical analyses a coefficient of variation (CV) of maximum $5 \%$ was allowed among replicates of a sample. In case of higher variation a new analysis was made.

For statistical analysis a one-way ANOVA (analysis of variance) with a post-hoc LSD (least significant difference)test was carried out using the program STATISTICA.

Correlation analyses were performed by the software Microsoft Excel between antioxidant capacity (FRAP analysis) and total phenolic compounds (TP analysis) results, using average values of the three cultivars at each sampling date.

The $p$-value used for reported statistical significance is 0.05 . 


\section{Results \\ Leaf length and dry matter}

Leaf length of the three studied cultivars increased $2-3 \mathrm{~cm}$ in every two weeks from the end of April until the beginning of June (Fig. 1). After this, leaf growth slowed down and almost stopped in the middle of July, reaching an average final leaf length of approximately $10 \mathrm{~cm}$. Leaves were initially longer in 'Otradnaja' but 'Ljubitelskaja' had the longest leaves from the beginning of June to the end of the sampling period.

Leaf dry matter content varied during the sampling period for all three cultivars, with comparatively low values between the end of May and the beginning of July (lowest average dry matter content for the three cultivars was less than $28 \%$ of fresh weight). After that, values increased until the end of July when the highest average dry matter content reached almost $32 \%$. The studied cultivars showed only minor differences in leaf dry matter development. Thus, leaves of 'Otradnaja' and 'Gibrid Pertjika' developed approximately in the same way, except for the last two sampling dates when dry matter of 'Gibrid Pertjika' increased more and reached almost 35\%. Dry matter content of 'Ljubitelskaja' decreased from the end of April to the middle of June and then increased again in July to a final dry matter content of about $31 \%$.

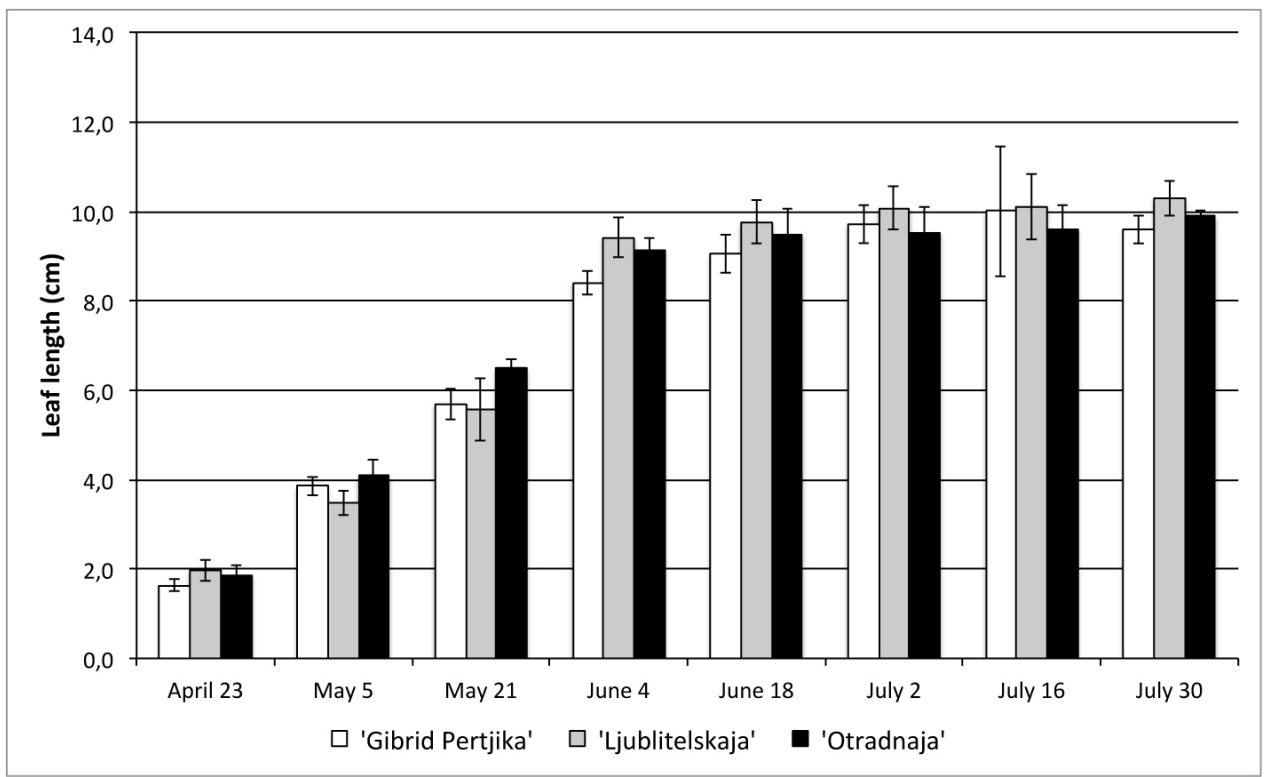

Fig. 1. Length of sea buckthorn leaves at different sampling dates for cvs. 'Otradnaja', ‘Gibrid Pertjika’and 'Ljubitelskaja'. Error bars represent standard deviation ( $n=12)$.

\section{Total phenolic compounds (TP) analysis}

The total content of phenolic compounds (average of single results for all cultivars) varied significantly during the sampling period (Fig. 2). Steady values on April 23 and May 7 (155 and 157 mg GAE/g dw, respectively) were followed by the lowest value on May 21 (122 mg GAE/g dw). After this, a small increase on June 4 (142 mg GAE/g $\mathrm{dw}$ ) was followed by a larger increase on July 16 and July 30 (to 176 and $185 \mathrm{mg} \mathrm{GAE} / \mathrm{g}$ dw, respectively). Pairwise comparisons showed a significant decrease and increase before and after May 21, respectively. A significant increase was also found between July 2 and July 16. Total phenolic compounds results of the last two sampling dates differed significantly from results at all other dates but not from each other.

The content of total phenolic compounds varied only slightly between the cultivars (Table 1). Cultivar 'Ljubitelskaja' had the highest content of total phenolic compounds at five out of eight sampling occasions. 


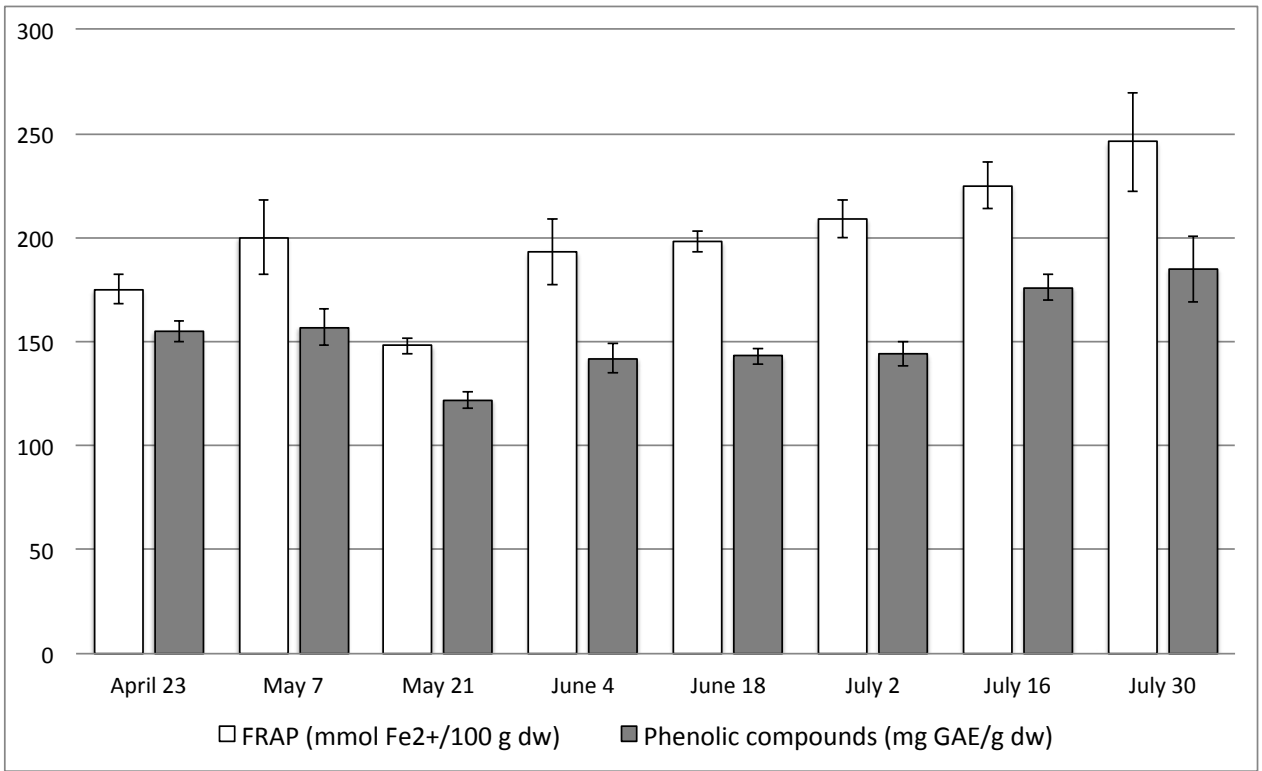

Fig. 2. Antioxidant capacity (FRAP analysis) and content of total phenolic compounds (Folin-Ciocalteu analysis) of sea buckthorn leaves (averages for separate samples of cvs 'Otradnaja', 'Gibrid Pertjika' and 'Ljubitelskaja'). GAE = gallic acid equivalents. Error bars represent standard deviation.

Table 1. Antioxidant capacity (FRAP analysis, $n=2$ ) and content of total phenols (Folin-Ciocalteu analysis, $n=2$ ) in sea buckthorn leaves for each sampling date and cultivar. For each analysis the average and standard deviation is presented (dw = dry weight, $\mathrm{GAE}=$ gallic acid equivalent).

\begin{tabular}{llllllllll}
\hline Analysis & Cultivar & April 23 & May 7 & May 21 & June 4 & June 18 & July 2 & July 16 & July 30 \\
\hline Antioxidant capacity & 'Otradnaja' & $176 \pm 3$ & $189 \pm 7$ & $147 \pm 4$ & $174 \pm 3$ & $203 \pm 2$ & $200 \pm 3$ & $216 \pm 1$ & $234 \pm 1$ \\
$\left(\mathrm{mmol} \mathrm{Fe}^{2+} / 100 \mathrm{~g} \mathrm{dw}\right)$ & 'Gibrid Pertjika' & $167 \pm 7$ & $189 \pm 5$ & $152 \pm 3$ & $195 \pm 5$ & $197 \pm 1$ & $208 \pm 2$ & $221 \pm 5$ & $226 \pm 2$ \\
& 'Ljubitelskaja' & $181 \pm 4$ & $223 \pm 5$ & $145 \pm 2$ & $211 \pm 2$ & $194 \pm 2$ & $219 \pm 4$ & $239 \pm 1$ & $276 \pm 4$ \\
Phenols & 'Otradnaja' & $154 \pm 8$ & $151 \pm 4$ & $125 \pm 4$ & $135 \pm 3$ & $148 \pm 4$ & $140 \pm 2$ & $172 \pm 5$ & $183 \pm 1$ \\
$\left(\mathrm{mg} \mathrm{GAE} \mathrm{g}{ }^{-1} \mathrm{dw}\right)$ & 'Gibrid Pertjika' & $154 \pm 0$ & $153 \pm 5$ & $125 \pm 1$ & $146 \pm 1$ & $143 \pm 2$ & $143 \pm 4$ & $176 \pm 8$ & $171 \pm 7$ \\
& 'Ljubitelskaja' & $158 \pm 2$ & $168 \pm 3$ & $118 \pm 2$ & $147 \pm 6$ & $140 \pm 1$ & $151 \pm 1$ & $183 \pm 6$ & $203 \pm 4$ \\
\hline
\end{tabular}

\section{FRAP analysis of antioxidant capacity}

Average content of total antioxidants for the three cultivars varied significantly between the sampling dates when determined by FRAP analysis (Fig. 2). Thus, the content increased from about 175 to $200 \mathrm{mmol} / 100 \mathrm{~g} \mathrm{dw}$ from April 23 to May 7, followed by a large decrease on May 21 when values reached a minimum ( $148 \mathrm{mmol} / 100 \mathrm{~g} \mathrm{dw}$ ). From June 4 to July 30, values increased steadily from 193 to $246 \mathrm{mmol} / 100 \mathrm{~g} \mathrm{dw}$. The average FRAP value on the last sampling date (July 30) was significantly higher compared to all other dates, except for July 16.

There were only minor differences in antioxidant capacity between the cultivars, 'Otradnaja' and 'Gibrid Pertjika' being more similar compared to 'Ljubitelskaja'. Cultivar 'Ljubitelskaja' had the highest FRAP values six out of eight sampling occasions.

Antioxidant capacity and the content of total phenolic compounds of the sea buckthorn leaves developed similarly during the sampling period. The correlation coefficient $(r)$ for antioxidant capacity and total phenolic compounds was 0.864 . 


\section{HPLC-MS analysis of major single phenolic compounds}

HPLC-MS chromatograms of all standards used and a representative chromatogram of a sample based on all ions selected are presented in Figure 3. Chromatograms for each ion that was extracted and quantified are shown in Figure 4.
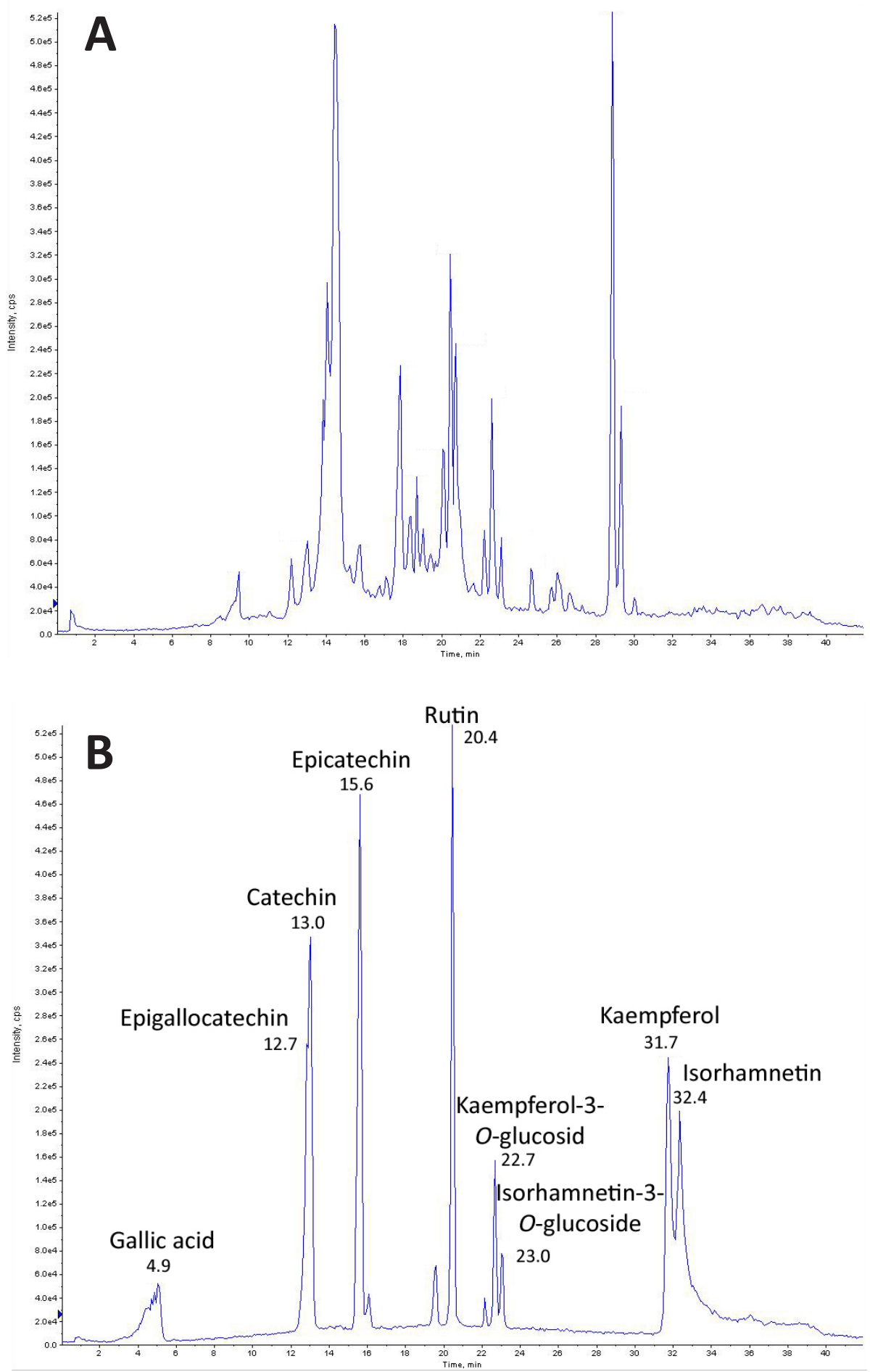

Fig. 3. MS traces based on 23 [M-H] ions shown for A) a representative leaf sample of cv. 'Ljubitelskaja' (July 2) and B) for the standards that were used for identification and quantification. For the standards the retention times are also presented. 
A

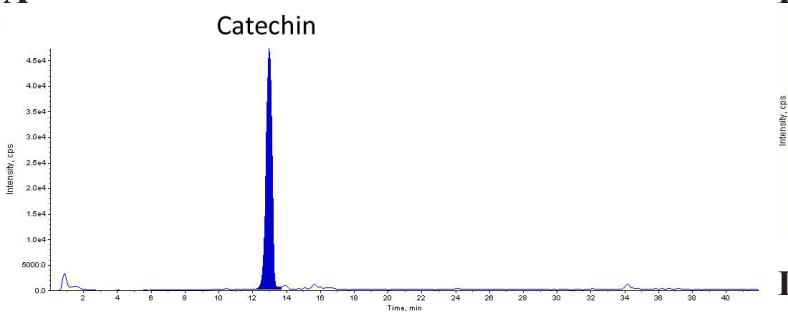

B

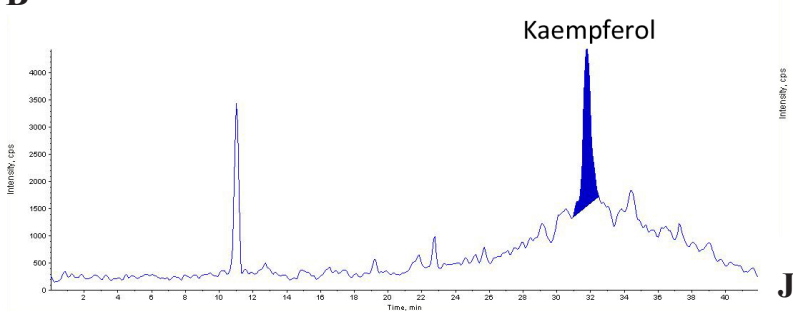

C

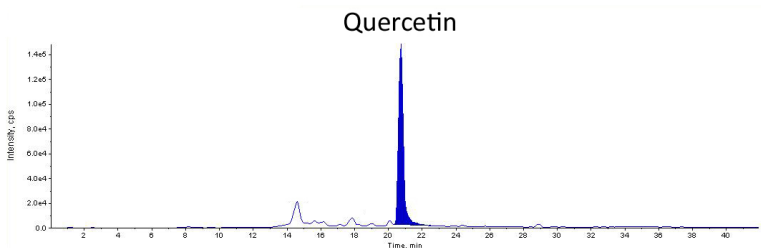

D

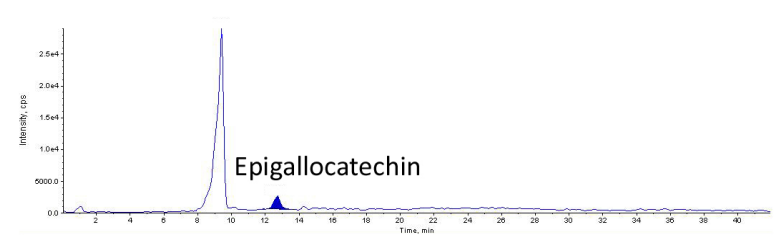

E

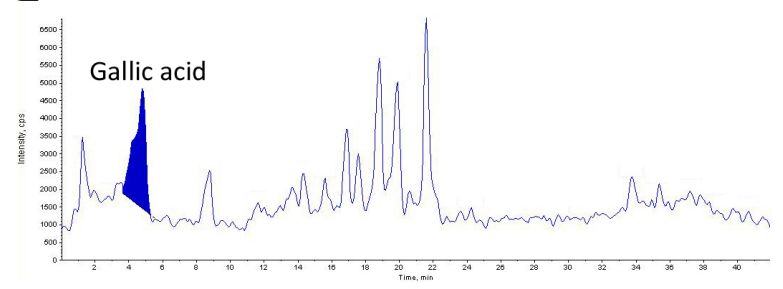

F

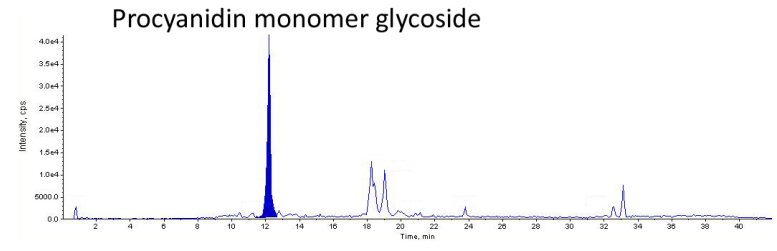

G

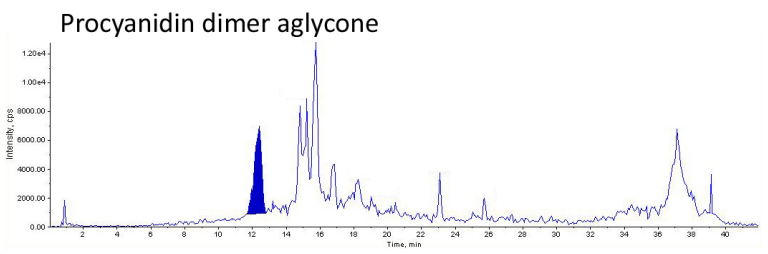

H

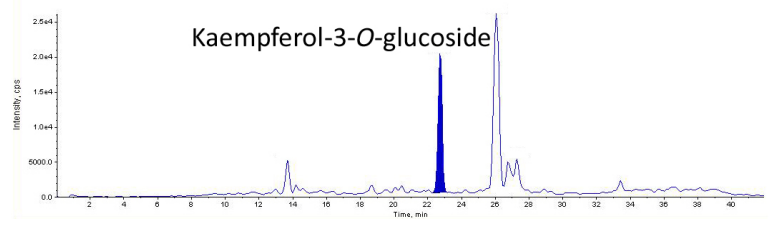

I
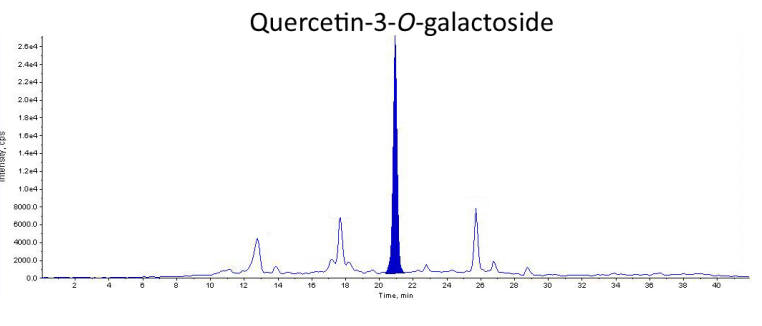

$\mathbf{J}$

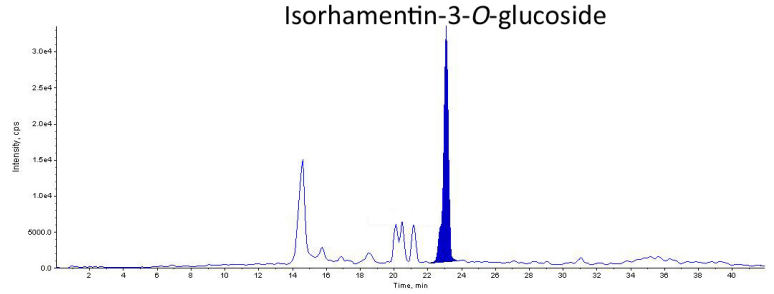

K

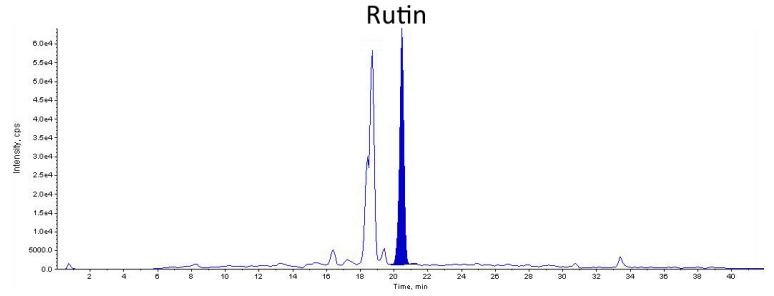

$\mathbf{L}$

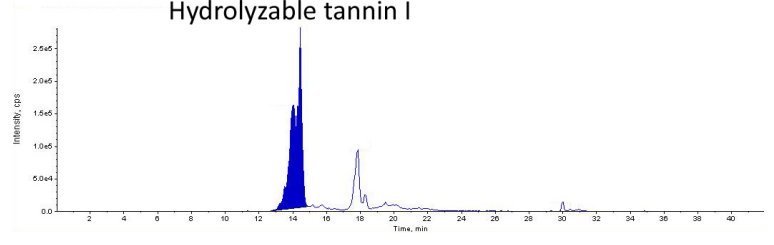

M

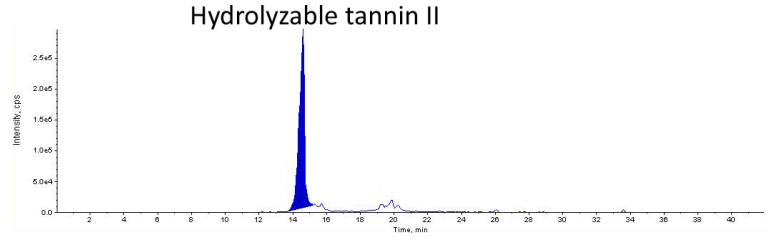

N

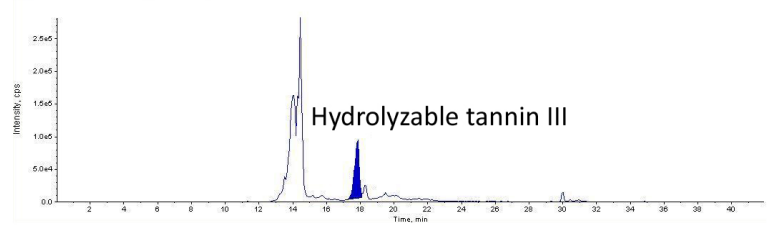

Fig. 4. MS traces of a leaf sample of cv 'Ljubitelskaja' for A) catechin ( $\mathrm{m} / \mathrm{z} 289.1, \mathrm{rt} 13.0)$, B) kaempferol (m/z 285.1, rt 31.7), C) quercetin (m/z 301.2, rt 20.7), D) epigallocatechin (m/z 305.2, rt 12.7), E) kaempferol-3-O-glucoside (m/z 447.3, rt 22.7), F) quercetin-3-Ogalactoside (m/z 463.4, rt 20.9), G) isorhamnetin-3-O-glucoside ( $\mathrm{m} / \mathrm{z} 477.4$, rt 23.0), H) rutin (m/z 609.5, rt 20.4), I) gallic acid ( $\mathrm{m} / \mathrm{z} 169.1$, rt 4.9), J) procyanidin monomer glycoside ( $\mathrm{m} / \mathrm{z} 451.2$, rt 12.2), K) procyanidin dimer aglycone (m/z 577.2, rt 12.4), L) hydrolyzable tannin I (m/z 935.5, rt 14.2, double peak), M) hydrolyzable tannin II (m/z 953.5, rt 14.6) and N) hydrolyzable tannin III (m/z 935.5, rt 17.8). 
A. Morgenstern et al. (2014) 23: 207-219

The content of each of the major single phenolic compounds quantified in leaves of 'Ljubitelskaja 'varied among sampling dates (except for kaempferol) but in different directions (Table 2). The content of catechin ( $\mathrm{m} / \mathrm{z} 289.1$, rt 13.0) did not change from April 23 to May 7, but decreased on May 21 followed by a continuous increase for the rest of the sampling period. A higher content than on any other date was obtained on July $30\left(958 \mu \mathrm{g} \mathrm{g}^{-1} \mathrm{dw}\right)$.

The content of kaempferol ( $\mathrm{m} / \mathrm{z} 285.1$, rt 31.7) was lower than the content of most of the other studied phenolic compounds, fluctuating between 2.8 and $4.3 \mu \mathrm{g} \mathrm{g} \mathrm{g}^{-1} \mathrm{dw}$ throughout the sampling period.

In contrast, the content of quercetin (m/z 301.2, rt 20.7) was high, with a steady increase from April to July, and the highest content was obtained on July $30\left(1381 \mu \mathrm{g} \mathrm{g}^{-1} \mathrm{dw}\right)$.

The highest content of epigallocatechin (m/z 305.2, rt 12.7) with $48 \mu \mathrm{g} \mathrm{g}^{-1} \mathrm{dw}$ was already reached on April 23. Levels decreased in May and then slightly increased to the end of July reaching $26 \mu \mathrm{g} \mathrm{g}^{-1} \mathrm{dw}$.

The highest content of kaempferol-3-O-glucoside (m/z 447.3, rt 22.7) was also reached at the two earliest sampling dates (101 and $104 \mu \mathrm{g} \mathrm{g}^{-1} \mathrm{dw}$, respectively). Subsequently, kaempferol-3-O-glucoside decreased until the end of the sampling period reaching $56 \mu \mathrm{g} \mathrm{g}^{-1} \mathrm{dw}$ at July 30 .

The content of quercetin-3-O-galactoside (m/z 463.4, rt 20.9) decreased similar as the content of kaempferol-3-O-glucoside. The highest content was noted for April 23 (458 $\mu \mathrm{g} \mathrm{g}^{-1} \mathrm{dw}$ ) and the lowest on July 16 (199 $\mu \mathrm{g}$ $\left.\mathrm{g}^{-1} \mathrm{dw}\right)$.

The content of isorhamnetin-3-O-glucoside (m/z 477.4, rt 23.0) was more or less the same during the sampling period. The highest content was reached at the last sampling dates (342 and $339 \mu \mathrm{g} \mathrm{g}^{-1} \mathrm{dw}$ on July 16 and 30 , respectively).

In contrast, the content of rutin $(\mathrm{m} / \mathrm{z} 609.5, \mathrm{rt} 20.4)$ decreased considerably during the sampling period. The highest content was reached on April $23\left(1310 \mu \mathrm{g} \mathrm{g}^{-1} \mathrm{dw}\right)$. Then the content decreased, and the lowest content was obtained in the middle of July $\left(387 \mu \mathrm{g} \mathrm{g}^{-1} \mathrm{dw}\right)$.

Also the content of gallic acid (m/z 169.1, rt 4.9) decreased almost 10 times during the sampling period with the lowest content being reached at the last sampling date $\left(39 \mu \mathrm{g} \mathrm{g}^{-1} \mathrm{dw}\right)$.

The content of procyanidin monomer glycoside (m/z 451.2, rt 12.2) instead increased largely from April 23 (5 $\mu \mathrm{g}$ $\left.\mathrm{g}^{-1} \mathrm{dw}\right)$ to July $30\left(383 \mu \mathrm{g} \mathrm{g} \mathrm{g}^{-1} \mathrm{dw}\right)$.

Also the content of procyanidin dimer aglycone (m/z 577.2, rt 12.4) increased during the sampling period and reached a maximum on July $30\left(205 \mu \mathrm{g} \mathrm{g}^{-1} \mathrm{dw}\right)$.

Hydrolyzable tannins I-III occurred in higher amounts than any other of the studied phenolic compounds. From a minimum on April 23 (1321 $\mu \mathrm{g} \mathrm{g}^{-1} \mathrm{dw}$ ), hydrolyzable tannin I (m/z 935.5, rt 14.2, double peak) increased especially at the beginning and middle parts of the sampling period, reaching its highest level on July $2\left(9809 \mu \mathrm{g} \mathrm{g} \mathrm{g}^{-1} \mathrm{dw}\right)$, and remaining approximately at the same level afterwards.

The content of hydrolyzable tannin II (m/z 953.5, rt 14.6) fluctuated during the entire sampling period, with significant increases and decreases. The highest content was found on June $4\left(10643 \mu \mathrm{g} \mathrm{g}^{-1} \mathrm{dw}\right)$ and the lowest on April 23 (4304 $\left.\mu \mathrm{g} \mathrm{g}^{-1} \mathrm{dw}\right)$.

Following an initial increase from April 23 to May 7 (5882 and $8944 \mu \mathrm{g} \mathrm{g}{ }^{-1} \mathrm{dw}$, respectively), hydrolyzable tannin III ( $\mathrm{m} / \mathrm{z} 935.5, \mathrm{rt} 17.8)$ mainly decreased towards the end of the sampling period. The lowest content $\left(1789 \mu \mathrm{g} \mathrm{g}^{-1}\right.$ $\mathrm{dw}$ ) was noticed for July 16 . 
A. Morgenstern et al. (2014) 23: 207-219

Table 2. Catechin, kaempferol, quercetin (quantified as rutin), epigallocatechin, kaempferol-3-O-glucoside, quercetin-3-O-galactoside (quantified as rutin), isorhamnetin-3-O-glucoside, rutin, gallic acid, procyanidin monomer glycoside and procyanidin dimer aglycone (quantified as catechin) as well as hydrolyzable tannins I-III (quantified as gallic acid) (HPLC-MS analysis) in sea buckthorn leaves of 'Ljubitelskaja' for each sampling date, respectively. For each compound the average (in $\mu \mathrm{g} / \mathrm{g}$ dry weight) and standard deviation $(n=3)$ is presented.

\begin{tabular}{|c|c|c|c|c|c|c|c|c|}
\hline Compound & April 23 & May 7 & May 21 & June 4 & June 18 & July 2 & July 16 & July 30 \\
\hline Catechin & $521 \pm 30$ & $548 \pm 20$ & $191 \pm 7$ & $282 \pm 34$ & $449 \pm 38$ & $595 \pm 38$ & $698 \pm 103$ & $958 \pm 344$ \\
\hline Kaempferol & $2.8 \pm 0.5$ & $4.2 \pm 1.0$ & $3.5 \pm 0.4$ & $3.3 \pm 0.7$ & $2.8 \pm 0.3$ & $4.3 \pm 0.8$ & $4.2 \pm 0.4$ & $4.1 \pm 0.2$ \\
\hline Quercetin & $332 \pm 22$ & $809 \pm 42$ & $939 \pm 27$ & $1145 \pm 99$ & $1138 \pm 97$ & $1358 \pm 228$ & $1243 \pm 41$ & $1381 \pm 107$ \\
\hline Epigallocatechin & $48 \pm 6$ & $41 \pm 3$ & $13 \pm 4$ & $17 \pm 3$ & $14 \pm 1$ & $22 \pm 1$ & $23 \pm 2$ & $26 \pm 2$ \\
\hline $\begin{array}{l}\text { Kaempferol-3- } \\
\text { O-glucoside }\end{array}$ & $101 \pm 10$ & $104 \pm 13$ & $85 \pm 5$ & $75 \pm 4$ & $69 \pm 6$ & $70 \pm 8$ & $54 \pm 3$ & $56 \pm 4$ \\
\hline $\begin{array}{l}\text { Quercetin-3- } \\
\text { O-galactoside }\end{array}$ & $458 \pm 5$ & $440 \pm 46$ & $373 \pm 14$ & $217 \pm 11$ & $230 \pm 13$ & $221 \pm 18$ & $199 \pm 16$ & $205 \pm 21$ \\
\hline $\begin{array}{l}\text { Isorhamnetin-3- } \\
\text { O-glucoside }\end{array}$ & $254 \pm 12$ & $293 \pm 32$ & $282 \pm 13$ & $227 \pm 11$ & $271 \pm 14$ & $308 \pm 56$ & $342 \pm 23$ & $339 \pm 9$ \\
\hline Rutin & $1310 \pm 144$ & $1270 \pm 182$ & $993 \pm 74$ & $711 \pm 28$ & $543 \pm 38$ & $545 \pm 72$ & $387 \pm 18$ & $471 \pm 20$ \\
\hline Gallic acid & $304 \pm 5$ & $267 \pm 13$ & $381 \pm 2$ & $293 \pm 8$ & $170 \pm 10$ & $72 \pm 1$ & $47 \pm 2$ & $39 \pm 1$ \\
\hline $\begin{array}{l}\text { Procyanidin } \\
\text { monomer } \\
\text { glycoside }\end{array}$ & $5 \pm 1$ & $9 \pm 3$ & $17 \pm 4$ & $57 \pm 2$ & $157 \pm 15$ & $250 \pm 6$ & $346 \pm 8$ & $383 \pm 26$ \\
\hline $\begin{array}{l}\text { Procyanidin } \\
\text { dimer aglycone }\end{array}$ & $38 \pm 5$ & $51 \pm 6$ & $16 \pm 4$ & $35 \pm 14$ & $62 \pm 11$ & $95 \pm 8$ & $137 \pm 24$ & $205 \pm 109$ \\
\hline $\begin{array}{l}\text { Hydrolyzable } \\
\text { tannin I }\end{array}$ & $1321 \pm 145$ & $3693 \pm 526$ & $2249 \pm 112$ & $7635 \pm 1062$ & $7842 \pm 731$ & $9809 \pm 832$ & $9737 \pm 929$ & $9753 \pm 790$ \\
\hline $\begin{array}{l}\text { Hydrolyzable } \\
\text { tannin II }\end{array}$ & $4304 \pm 601$ & $9273 \pm 1189$ & $4772 \pm 297$ & $10643 \pm 925$ & $6153 \pm 666$ & $7770 \pm 595$ & $6143 \pm 686$ & $7495 \pm 793$ \\
\hline $\begin{array}{l}\text { Hydrolyzable } \\
\text { tannin III }\end{array}$ & $5882 \pm 709$ & $8944 \pm 1415$ & $5108 \pm 533$ & $5061 \pm 790$ & $2595 \pm 459$ & $2854 \pm 259$ & $1789 \pm 230$ & $2640 \pm 306$ \\
\hline
\end{tabular}

\section{Discussion}

\section{Changing content during leaf development}

Dry matter content of the sea buckthorn leaves fluctuated during the entire sampling period. Beside genetic effects, precipitation and rate of leaf assimilation have probably contributed to these findings. In general, rainy weather is expected to result in lower dry matter content but in our study, dry matter increased to the highest values in July despite heavy rainfalls. The precipitation in April, May, June and July was 18, 45, 129 and $232 \mathrm{~mm}$ respectively (official data for Kristianstad, obtained from the Swedish Meteorological and Hydrological Institute). Furthermore, during July leaf growth (cell elongation) almost stopped. Since mature foliage leaves usually have higher assimilation rates compared to younger leaves, increased leaf maturation is the likely explanation to the increased content of dry matter towards the end of the sampling period.

Contents of total phenolic compounds and the antioxidant capacity values were highest in July, and thus accompanied the simultaneous increase in dry matter content. The highly significant correlations between antioxidant capacity and content of phenolic compounds are in agreement with previously published results (Singh 2006).

A few studies have previously reported about the content of total flavonoids and total flavones in sea buckthorn leaves, which the present study did not investigate. Sea buckthorn leaves contain about $3.8-4 \%$ of total flavonoids (Singh 2006, Tsybikova et al. 2006), and plants growing in the west Pamirs had flavonoid contents ranging from 310 to $1238 \mathrm{mg} / 100 \mathrm{~g}$ dry weight in the leaves (Singh 2006). Since these studies do not mention harvesting dates, a comparison with the results in the present study is difficult. Rongfu et al. (2003) however studied the influence of leaf developmental stage on total flavones in sea buckthorn leaves. Total flavones in H. rhamnoides of ssp. sinensis was reported to reach maximum levels during May-July, and then decreased from September onwards, to reach a minimum in the autumn. 


\section{Growing conditions and plant defense}

Environmental factors such as different field management practices have previously been reported to influence the content of antioxidant and phenolic substances in sea buckthorn leaves. Heinäaho et al. (2006) found that the content of phenolic compounds was significantly lower when plants were mulched with plastic compared to organic mulch treatments, e.g., conifer chips. In general, more phenolic compounds were produced when plants were grown on a flat surface compared to plants grown on low hills formed by an excavator. The flat ground was less aerated, and less solar heat was present, so that growing conditions were worse compared to the low hills. More phenolic substances, especially tannins, were produced, and it was suggested that this increase in phenol synthesis was caused by environmental stress to the plants. In the present study, plants were grown on a flat surface and no fertilizer or irrigation was used which may have favored production of a wider variety of plant phenolic compounds. The single phenolic compounds analyzed in our study showed much variation in contents from April to July, probably due to differences in synthesis, metabolism and functions in the plant. This may indicate that single phenolic compounds are produced by the plant when there is a need.

The antioxidant capacity and the content of phenolic substances may also have been influenced by pollutants or pests, since plants can form antioxidants and phenolic substances as a defense under stressful conditions. Mayr et al. (1997) investigated the phenolic compounds of apples and their relationship to resistance against the fungal disease apple scab, and found that leaves and fruits of resistant genotypes contained higher flavanol contents than leaves and fruits of non-resistant genotypes, with phenol biosynthesis obviously being important in the expression of resistance.

The major phenolic compounds investigated by HPLC-MS analysis in our study were dominated by the hydrolyzable tannins, which occurred in much higher amounts in sea buckthorn leaves compared to the other major phenolic compounds studied. Plant tannins have complex structures and can therefore be difficult to characterize and quantify. Based on mass number and fragments, hydrolyzable tannin I (m/z 935.5, rt 14.2, which occurred as a double peak in our analyzes) according to literature tentatively could be a mixture of stachyurin and casuarinin previously reported to be present in sea buckthorn leaves (Moilanen et al. 2013, Yoshida et al. 1991). Hydrolyzable tannin III (m/z 935.5, rt 17.8) could tentatively be casuarictin. For hydrolyzable tannin II (m/z 953.5, rt 14.6) we have found no matching information in the published literature.

Tannins are mainly located in the green parts of the sea buckthorn plant (Sheichenko and Tolachev 2006). Heinäaho et al. (2006) found that hydrolyzable and condensed tannins were the dominant phenolic groups in sea buckthorn leaves. Tsybikova et al. (2006) and Singh (2006) referred to studies that reported about 10-15\% tannins in leaves, $20-35 \%$ tannins in green shoots and only $0.13 \%$ tannins in fruits. During early growth of leaves, strictinin and isostrictinin were the predecessors of more complex tannins such as casuarinin, casuarictin and hippophaenin $B$, being accumulated in the later phases of growth. Maximum tannin content was found in the middle of July (Sheichenko and Tolachev 2006), which coincides approximately with the maximum of hydrolyzable tannin I ( $\mathrm{m} / \mathrm{z}$ 935.5, rt 14.2) in the present study. However, Sheichenko and Tolachev (2006) reported about the total tannin contents, whereas only some selected major tannins were investigated in the present study (HPLC-MS analysis). Besides, in our study not all tannins had their maximum content in July. The content of hydrolyzable tannin II $(\mathrm{m} / \mathrm{z}$ 953.5, rt 14.6) and III (m/z 935.5, rt17.8) was highest in the beginning of May.

Tannins are produced by many plant species as a chemical weapon against herbivores that avoid plants or parts of plants with high tannin contents. Since sea buckthorn plants in general contain high amounts of different tannins, these may constitute an important defense system against attacks of herbivores, such as Cacopsylla hippophaës Foerster (a psyllid), Capitophorus hippophaës Walker (an aphid) or Eriophyes hippophaënus Nalepa (a mite) all of which were found in the field where plants were harvested for leaves in our study. 


\section{Genetic variation}

When single phenolic compounds in the leaves were analyzed we found that quercetin and hydrolyzable tannins were present in the highest amounts. This confirms the results of Rongfu et al. (2003) who found that quercetin was the main component of total flavones in $H$. rhamnoides leaves, while isorhamnetin constituted $64 \%$ of the total flavones in $\mathrm{H}$. tibetana leaves. Kaempferol content was higher in the original Chinese material of $\mathrm{H}$. rhamnoides of ssp. sinensis, than in the introduced Russian forms (Rongfu et al. 2003). The content of phenolic compounds thus seems to vary among species and subspecies, but there is also variation in phenolic content among different cultivars of the same species as revealed in the present study. In most cases during the sampling period, 'Ljubitelskaja' had higher total antioxidant capacity and total phenol content than 'Otradnaja' and 'Gibrid Pertjika'. Cultivar 'Ljubitelskaja' was therefore used for a detailed HPLC-MS analysis.

All three cultivars investigated in this study, are Russian hybrids between subsp. mongolica and subsp. rhamnoides. When analyzed with DNA markers (RAPD) together with a set of 52 other cultivars and hybrids of sea buckthorn, these three occurred in the same main cluster together with other hybrids and a few representatives of the parental subspecies (Bartish et al. 2001). However, while 'Otradnaja' and 'Gibrid Pertjika' were relatively close together also in a more narrowly defined subcluster, 'Ljubitelskaja' belonged to a different subcluster indicating that it is less closely related to the other two. Similarly, in our study 'Ljubitelskaja' was relatively more dissimilar in leaf size and chemical contents (higher antioxidant capacity at four out of eight dates, and higher total phenol content at two dates) compared to the other two cultivars that rarely differed.

\section{Conclusions}

Total antioxidant capacity and content of total phenolic compounds in sea buckthorn leaves increased during leaf development, and were highest at the end of July when the last sampling was undertaken. However if maximum levels of single major phenolic compounds are desired due to specific bioactive benefits, the content of each single phenolic compound must be considered since not every compound had its maximum in fully developed leaves. Total yield of bioactive compounds is then depending on the cultivar and yield of leaves, which must also be considered in a commercial production. A detailed characterization of sea buckthorn leaf phenolic compounds would contribute with valuable information and remains to be investigated.

\section{Acknowledgements}

This study would not have been possible without access to plant material from the ongoing sea buckthorn breeding program at the Department of Plant Breeding, Balsgård supported by The Swedish University of Agricultural Sciences and The Swedish Research Council Formas. Hilde Nybom is acknowledged for providing valuable comments to the manuscript.

\section{References}

Arimboor, R., Kumar, K.S. \& Arumughan, C. 2008. Simultaneous estimation of phenolic acids in sea buckthorn (Hippophaë rhamnoides) using RP-HPLC with DAD. Journal of Pharmaceutical and Biomedical Analysis 47: 31-38.

Bartish G.I., Jeppsson N., Bartish I.V. \& Nybom H. 2001. Assessment of genetic diversity using RAPD analysis in a germplasm collection of sea buckthorn. Agricultural and Food Science 9: 279-288.

Benzie, I.F.F. \& Strain, J.J. 1996. The ferric reducing ability of plasma (FRAP) as a measure of „antioxidant power“: The FRAP assay. Analytical Biochemistry 239: 70-76.

Erkkola, R. \& Yang, B. 2003. Sea buckthorn oils: towards healthy mucous membranes. Women`s Health, AgroFood industry hitech 3: 53-57.

Geetha, S., Sai Ram, M., Singh, V., Ilavazhagan, G. \& Sawhney, R.C. 2002. Antioxidant and immunomodulatory properties of sea buckthorn (Hippophae rhamnoides) - an in vitro study. Journal of Ethnopharmacology 79: 373-378.

Heinäaho, M., Pusenius, J., Julkunen-Tiitto, R. 2006. Effects of different organic farming methods on the concentration of phenolic compounds in sea buckthorn leaves. Journal of Agricultural and Food Chemistry 54: 7678-7685.

Jain M., Ganju L., Katiyal A., Padwad Y., Mishra K.P., Chanda S., Karan D., Yogendra K.M. \& Sawhney R.C. 2008. Effect of Hippophae rhamnoides leaf extract against Dengue virus infection in human blood-derived macrophages. Phytomedicine 15: 793-799.

Jayashankar, B., Mishra, K.P., Kumar, M.S.Y., Udayasankar, K., Misra, K., Ganju, L. \& Singh, S.B. 2012. A supercritical CO2 extract from seabuckthorn leaves inhibits pro-inflammatory mediators via inhibition of mitogen activated protein kinase p38 and transcription factor nuclear factor-kB. International Immunopharmarmacology 13: 461-467. 
A. Morgenstern et al. (2014) 23: 207-219

Johansson, A., Korte, H., Yang, B., Stanley, J. \& Kallio, H. 2000. Sea buckthorn berry oil inhibits platelet aggregation. Journal of Nutrition and Biochemistry 11: 491-495.

Kim, J.S., Kwon, Y.S., Sa, Y.J. \& Kim, M.J. 2011. Isolation and identification of sea buckthorn (Hippophae rhamnoides) phenolics with antioxidant activity and a-glucosidase inhibitory effect. Journal of Agricultural Food Chemistry 59: $138-144$.

Larmo, P., Alin, J., Salminen, E., Kallio, H. \& Tahvonen, R. 2008. Effects of sea buckthorn berries on infections and inflammation: a double- blind, randomized, placebo-controlled trial. European Journal of Clinical Nutrition 62, 1123-1130.

Larmo, P.S., Järvinen, R.L., Setälä, N.L., Yang, B., Viitanen, M.H., Engblom, J.R., Tahvonen, R.L. \& Kallio, H.P. 2010. Oral sea buckthorn oil attenuates tear film osmolarity and symptoms in individuals with dry eye. Journal of Nutrition 140: 1462-1468.

Larmo, P.S., Yang B., Hurme, S.A., Alin, J.A., Kallio, H.P., Salminen, E.K. \&Tahvonen, R.L. 2009. Effect of a low dose of sea buckthorn berries on circulating concentrations of cholesterol, triacylglycerols, and flavonols in healthy adults. European Journal of Nutrition 48: 277-282.

Lehtonen, H.-M., Järvinen, R., Linderborg, K., Viitanen, M. Venojärvi, M., Alanko, H. \& Kallio, H. 2010a. Postprandial hyperglycemia and insulin response are affected by sea buckthorn (Hippophaë rhamnoides ssp. turkestanica) berry and its ethanol-soluble metabolites. European Journal of Clinical Nutrition 58: 620-627.

Lehtonen, H.M., Lehtinen, O., Suomela, J.P., Viitanen, M. \& Kallio H. 2010b. Flavonol glycosides of sea buckthorn (Hippophae rhamnoides ssp. sinensis) and lingonberry (Vaccinium vitis-idaea) are bioavailable in humans and monoglucuronidated for excretion. Journal of Agricultural Food Chemistry 58: 620-627.

Mayr, U., Michalek, S., Treutter, D. \& Feucht, W. 1997. Phenolic compounds of apple and their relationship to scab resistance. Journal of Phytopathology 145: 69-75.

Moilanen, J., Sinkkonen, J. \& Salminen, J.-P. 2013. Characterization of bioactive plant ellagitannins by chromatographic, spectroscopic and mass spectrometric methods. Chemoecology 23: 165-179.

Padwad, Y., Ganju, L., Jain, M., Chanda, S., Karan, D., Kumar Banerjee, P. \& Chand Sawhney, R. 2006. Effect of leaf extract of seabuckthorn on lipopolysaccharide induced inflammatory response in murine macrophages. International Immunopharmacology 6: 46-52.

Qinxiao, W., Hongyan, Z. 2003. Sea buckthorn for the control of soil erosion in mountainous lands. In: Singh, V. (ed.) Sea buckthorn (Hippophae L.) - A multipurpose wonder plant. Vol. I: Botany, harvesting and processing technologies. New Delhi: Indus Publishing Company. p. 401-408.

Rongfu, S., Chunhong, W., Yonghai, L., Zhongping, W., Shuangmin, X. \& Qingping, G. 2003. The studies on the content and variation regularity of flavone active component in sea buckthorn leaves. The global sea buckthorn research and development 1: $41-47$.

Ruan, C-.J., Rumpunen, K. \& Nybom, H. 2013. Advances in improvement of quality and resistance in a multipurpose crop: sea buckthorn. Critical Reviews in Biotechnology 33: 126-144.

Rösch, D., Bergman, M., Knorr, D. \& Kroh, L. 2003. Structure-antioxidant efficiency relationships of phenolic compounds and their contribution to the antioxidant activity of sea buckthorn juice. Journal of Agricultural and Food Chemistry 51: 4233-4239.

Saggu, S., Divekar, H.M., Gupta, V., Sawhney, R.C., Banerjee, P.K. \& Kumar, R. 2007. Adaptogenic and safety evaluation of sea buckthorn (Hippophae rhamnoides) leaf extract: a dose dependent study. Food and Chemical Toxicology 45: 609-617.

Saggu, S. \& Kumar R. 2008. Effect of seabuckthorn leaf extracts on circulating energy fuels, lipid peroxidation and antioxidant parameters in rats during exposure to cold, hypoxia and restraint (C-H-R) stress and post stress recovery. Phytomedicine 15: $437-446$.

Salminen, J.-P., Ossipov, V., Loponen, J., Haukioja, E., \& Pihlaja, K. 1999. Characterisation of hydrolysable tannins from leaves of Betula pubescens by high-performance liquid chromatography-mass spectrometry. Journal of Chromatography A 864: $283-291$.

Sheichenko, O.P. \& Tolkachev, O.N. 2006. Tannins of sea buckthorn (Hippophae rhamnoides L.): chemical properties and biological action. In: Singh, V. (ed.) (2006) Sea buckthorn (Hippophae L.) - A multipurpose wonder plant. Vol. II. Biochemistry and pharmacology. New Delhi: Daya Publishing House. p. 197-213.

Singh, V. 2003. Geographical adaption and distribution of sea buckthorn (Hippophae L.) resources._In: Singh, V. (Ed.) Sea buckthorn (Hippophae L.) - A multipurpose wonder plant. Vol. I: Botany, harvesting and processing technologies. New Delhi: Indus Publishing Company. p. 21-34.

Singh, V. 2006. Free radicals, diseases, antioxidants and antioxidant properties of sea buckthorn (Hippophae rhamnoides L.). In: Singh, V. (ed.) Sea buckthorn (Hippophae L.) - A multipurpose wonder plant. Vol. II: Biochemistry and pharmacology. New Delhi: Daya Publishing House. p. 3-69.

Singleton, V.L. \& Rosst, J.A. 1965. Colourmetry of total phenolics with phosphomolybdic-phosphotungstick acid reagents. American Journal of Enology and Viticulture 16: 144-158.

Swensson, U. \& Bartish, I.V. 2003. Taxonomic synopsis of Hippophae (Elaeagnaceae). Nordic Journal of Botany 22: 369-374.

Tolkachev, O.N. \& Sheichenko, O.P. 2006. Flavonoids of sea buckthorn (Hippophae rhamnoides L.): chemistry and pharmacology. In: Singh, V. (Editor) (2006) Sea buckthorn (Hippophae L.) - A multipurpose wonder plant. Vol. II. Biochemistry and pharmacolog. New Delhi: Daya Publishing House. p. 159-167.

Tsybikova, D.Ts., Rasputina, D.B. \& Komissarenko, N.F. 2006. Flavonoids and other biologically active substances of sea buckthorn leaves. In: Singh, V. (ed.) Sea buckthorn (Hippophae L.) - A multipurpose wonder plant. Vol. II: Biochemistry and pharmacology. New Delhi: Daya Publishing House. p. 168-176.

Upadhyay, N.K., Kumar, R., Siddiqui, M.S. \& Gupta, A. 2011. Mechanism of wound-healing activity of Hippophae rhamnoides L. leaf extract in experimental burns. Evidence Based Complementary and Alternative Medicine Article ID 659705, pp. 9.

Upadhyay, N.K., Kumar M.S. \& Gupta, A. 2010. Antioxidant, cytoprotective and antibacterial effects of sea buckthorn (Hippophae rhamnoides L.) leaves. Food and Chemical Toxicology 48: 3443-3448. 
Yang, B., Kalimo, K.O., Mattila, L.M., Kallio, S.E., Katajisto, J.K., Peltola, O.J. \& Kallio, H.P. 1999. Effects of dietary supplementation with sea buckthorn (Hippophaë rhamnoides) seed and pulp oils on atopic dermatitis. Journal of Nutritional Biochemistry 10: 622-630. Yoshida, T., Tanaka, K., Chen, X.-M. \& Okuda, T. 1991. Tannins from Hippophae rhamnoides. Phytochemistry 30: 663-666.

Zu, Y., Li, C., Fu, Y. \& Zhao, C. 2006. Simultaneous determination of catechin, rutin, quercetin kaempferol and isorhamnetin in the extract of sea buckthorn (Hippophae rhamnoides L.) leaves by RP-HPLC with DAD. Journal of Pharmaceutical and Biomedical Analysis 41: 714-719. 